(c) American Dairy Science Association, 2003.

\title{
Genetic Parameters for Feet and Leg Traits Evaluated in Different Environments
}

\author{
J. Fatehi, ${ }^{\star}$ A. Stella, ${ }^{\star, 1}$ J. J. Shannon, $†$ and P. J. Boettcher, ${ }^{\star 2}$ \\ ${ }^{*}$ Center for Genetic Improvement of Livestock \\ Department of Animal and Poultry Science, \\ University of Guelph, Ontario, Canada N1G 2W1 \\ †Holstein Canada \\ Brantford, Ontario, Canada N3T 5K4
}

\section{ABSTRACT}

The objective of this study was to test for genotype $\times$ environmental interaction (GXE) for feet and leg traits scored in different environments. Genetic correlations of seven feet and leg traits were estimated across different management systems: free versus tie stalls, slatted versus solid flooring, and intact versus trimmed hooves. Data were records from first-lactation Holstein cattle. Traits were claw uniformity, depth of heel, rear leg rear view, foot angle, bone quality, rear leg side view, and overall feet and legs. Different subsets of data were used for each comparison, resulting in 147,400; 53,550; and 145,160 records for housing, flooring, and hoof trimming management systems, respectively. Genetic parameters were estimated using REML and two-trait models in which for each animal a given trait was observed in one environment and missing in the other. Phenotypic scores were lower with tie stalls, slatted floors, and no trimming. Heritabilities tended to be greater in herds with tie stalls and slatted floors. Trimming had little effect on genetic parameters. The genetic correlations of feet and leg traits across pairs of management systems were $\geq 0.85$, except for rear legs, rear view. Therefore, effects of GXE were assumed to be of little importance and modification of genetic evaluation procedures on the basis of housing, flooring, and hoof conditions seems unnecessary.

(Key words: genotype $\times$ environment interaction, conformation, housing, management)

\footnotetext{
Abbreviation key: GXE = genotype $\times$ environmental interaction.

Received October 4, 2001.

Accepted December 11, 2001.

Corresponding author: P. J. Boettcher; e-mail: paulboettcher@ anafi.it.

${ }^{1}$ Current address: CERSA, Via Fratelli Cervi 93, 20090 Segrate (MI), Italy.

${ }^{2}$ ANAFI, Via Bergamo 292, 26100 Cremona, Italy.
}

\section{INTRODUCTION}

Lameness in one of the most costly diseases of dairy cattle (Enting et al., 1997). Direct costs of lameness include the costs of equipment, facilities, and chemicals for prevention and treatment, veterinary costs and increased labor. Indirect costs are also important. Feet and leg disorders are one of the most common reasons for involuntary culling in dairy cattle. Results of a survey by the National Animal Health Monitoring System (APHIS, 1996) reported that $15.0 \%$ of all culling was directly due to lameness or injury. According to this report, among factors associated with involuntary culling, only reproductive problems $(26.7 \%)$ and udder and mastitis problems $(26.5 \%)$ were cited more frequently as reasons for disposal. Feet and leg problems can contribute indirectly to culling for reproductive failures by decreasing expression of estrus. Increased open days, longer calving interval, and eventually lower profit and involuntary culling are the consequences of reproductive problems caused indirectly by feet and leg disorders.

The direct and indirect consequences of feet and leg problems can be reduced by selection. Two main pathways exist by which genetics can effect resistance to feet and leg disorders: metabolically and through structural differences in body conformation (McDaniel, 1997). The approach generally taken by breeding organizations is to emphasize the structural differences in the feet and legs of cattle. These structural differences can be scored directly by observation or measurement. On the basis of the linear type scoring systems introduced in the early 1980 s, selection programs for conformation traits became more objective (Boelling and Pollott, 1998). Positive relationships between feet and leg traits and herd life have been shown in numerous studies (e.g., Foster et al., 1989; Boettcher et al., 1997; Passman and Reinhardt, 1999). Many countries include some measure of feet and legs conformation in their selection programs, often as a predictor of longevity (e.g., DeJong et al., 1999).

In addition to genetic effects, environmental factors also influence feet and leg traits. Diet, housing, and general management all affect the health of feet and legs 
(Enevoldsen et al., 1991; Greenough and Weaver, 1997). Therefore, the way in which cattle are managed could have an effect on their type scores for feet and legs. For example, tie stalls are likely to generally provide a drier environment than are free stalls. Cows in free stalls have more ability to move around and may have more opportunity for exercise. Among free-stall systems of housing, different flooring types could cause differences in scores for feet and leg traits. Some systems may be more challenging to the health of feet and legs. Scoring for these traits may also be affected by hoof trimming. In general, foot trimming is performed to minimize locomotive problems. Some breeders trim the feet of their cattle a short time before classification, to improve type scores. Thus, one might expect that mean scores for feet and leg traits would be higher in herds that regularly trim hooves than in herds that do not. In addition, variability could be reduced in these herds for some of the feet and leg traits.

Vermunt et al. (1996) found significant differences in claw conformation between the heifers that are housed indoors on concrete slats and kept out of doors in a dry lot. Gilmore (1978) indicated that measurements of foot structure were affected by a number of environmental factors, including type of housing (free stall vs. tie stall), age, breed, and time after trimming. He reported that $39 \%$ of variation in the length of rear claw was explained by breed, age, housing, time and interactions.

Differences in management among herds could have implications in genetic evaluations of type traits. If differences in phenotypic variability exist in different environments, then heritabilities may differ as well. Trimming may reduce the genetic variability of certain traits and thus decrease the heritability and accuracy of genetic evaluations. Problems transmitted by certain bulls will not be as evident if a large proportion of their daughters are treated for these problems by trimming before classification. Differences in management of cattle with respect to feet and legs could also cause genotype $\times$ environment interaction (GXE) among the feet and leg traits. For example, perhaps in free-stall environments, characteristics of the foot and hoof that resist effects of moisture would be more important than in tie-stall herds. These factors may affect the relationships between feet and legs and longevity. Burke and Funk (1993) reported that the relationship between locomotive traits and herd life differed by housing system.

To address concerns among breeders, in 1998 the Canadian Holstein Association began a program to record certain management factors at the herd level at each round of classification. The objective of this study was to use this information to test for genetic differences between the feet and leg traits for cows managed differently according to these management factors. The factors examined in this study were stall type (free vs. tie), flooring type (solid vs. slatted within free-stall herds), and frequency of trimming. Heritabilities of the feet and leg traits were estimated within these environments and genetic correlations were estimated for the same trait across environments.

\section{MATERIALS AND METHODS}

Data were records of type classification and herd management surveys from the Canadian Holstein Association. The traits involved in the analysis were rear legs from the side and rear views, bone quality, foot angle, depth of heel, claw uniformity, and overall feet and leg conformation. Foot angle, heel depth, and claw uniformity are, in general, traits that describe the foot or the claw. Bone quality and rear legs, rear view describe the legs. Rear legs, rear view can be influenced by both the claw and the position of the thurls. All traits were scored on pseudo-continuous scales. This scale ranged from 1 to 9 for the first six traits and from 1 to 18 for overall feet and legs. For all traits except rear legs, side view, higher values are generally considered favorable. Table 1 has a brief description for each of the different traits. Additional details about these traits can be obtained from Holstein Canada (www.holstein.ca) of Brantford, Ontario.

Data were collected between March, 1998, and May, 2000. Before March, 1998 rear legs from the rear view, heel depth, and claw uniformity had not been recorded. In addition, March, 1998, marked the initiation of the herd management surveys. Data were edited to include only the first available records from cows in their first lactations. In addition, cows were required to be between 20 and 35 mo of age at calving and only classifications during the first $335 \mathrm{~d}$ of lactation were considered.

The herd management surveys included four questions. The first dealt with type of housing and responses could be either tie stall, free stall, or other (including a combination of the two). The second question dealt with flooring and possible responses were cement (solid), slatted, or other. The final two dealt with hoof trimming. The first asked if hoof trimming had ever been done in the herd, and the other asked if hoof trimming was recently performed, with the definition of recent being within the previous 3 mo.

Three sets of data were obtained by grouping herds according to the results of the management surveys. To avoid problems associated with changes in environments for given cows, only those herds that answered all of the questions in the same way throughout the study period were considered. Most of the herds had been classified multiple times during the data collection period. The first dataset included data from the herds that had either 
Table 1. Descriptions of the traits analyzed in this study.

\begin{tabular}{|c|c|c|c|}
\hline Trait & Criterion & Low score & High score \\
\hline Rear legs, rear view & $\begin{array}{l}\text { Deviance of rear legs from imaginary } \\
\text { perpendicular lines connecting pin } \\
\text { bones and floor }\end{array}$ & $\begin{array}{l}\text { Hocks are inside of } \\
\text { perpendicular lines and toes } \\
\text { are outside of lines }\end{array}$ & $\begin{array}{l}\text { Rear legs perpendicular with } \\
\text { floor }\end{array}$ \\
\hline Bone quality & $\begin{array}{l}\text { Degree of flatness of bone in thigh } \\
\text { and flank regions }\end{array}$ & Coarse and round boned & $\begin{array}{l}\text { Extremely flat and refined with } \\
\text { tendons well defined }\end{array}$ \\
\hline Rear legs, side view & Angle of hock & High angle, straight leg & Low angle, curved leg \\
\hline Feet and legs & $\begin{array}{l}\text { Combination of all traits and } \\
\text { mobility (when observable) }\end{array}$ & $\begin{array}{l}\text { Low scores for all } \\
\text { individual traits }\end{array}$ & $\begin{array}{l}\text { High scores for all traits with no } \\
\text { visible defects }\end{array}$ \\
\hline
\end{tabular}

tie or free stalls throughout the recording period. Herds with another type of housing were not considered. The second data set considered only free-stall herds, and grouped herds according to solid or slatted flooring. The third dataset divided herds on the basis of whether the cows had been recently trimmed or not. The housing dataset included 147,400 observations (93,664 tie stall and 53,736 free stall). The flooring set included 53,550 records (47,997 solid and 5553 slatted). The trimming file contained 145,160 records $(78,063$ intact and 67,097 trimmed).

A preliminary analysis used a simple ANOVA to test for effects of the different environmental groups on the traits. This model included fixed effects of the management system (e.g., tie vs. free stalls), stage of lactation, age at scoring, round and classifier, and sire.

Genetic parameters for the seven traits across the environments were estimated using REML and a series of two-trait animal models. Each of the seven feet and leg traits was dealt with separately. For each analysis, trait 1 was a given trait scored in one environment (tie stall, for example) and trait 2 was the same measure scored in the different environment (i.e., free stall). Each cow thus had the data observed for one trait and missing for the other.

The following multiple trait animal model equation was applied for estimation of variance components:

$$
\begin{gathered}
y_{i j k l m}=\mu+S_{i}+R C_{j}+H R C_{k}+\beta_{1} X_{a g e}+\beta_{2}\left(X_{a g e}\right)^{2}+A_{l} \\
+e_{i j k l},
\end{gathered}
$$

where

$$
\begin{aligned}
y_{i j k l m}= & \text { dependent variable, a score for a feet and } \\
& \text { leg trait scored in either a tie stall or free- } \\
& \text { stall housing, on a solid or slatted floor, and } \\
& \text { in a hoof trimmed or nontrimmed animal. }
\end{aligned}
$$

$$
\begin{aligned}
\mu= & \text { overall mean, } \\
S_{i}= & \text { fixed effect of } \mathrm{i}^{\text {th }} \text { stage of lactation at classi- } \\
& \text { fication, } \\
R C_{j}= & \text { fixed effect of } \mathrm{j}^{\text {th }} \text { round-classifier, } \\
H R C_{k}= & \text { random effect of } \mathrm{k}^{\text {th }} \text { herd-rounder-classi- } \\
& \text { fier, } \\
\beta_{1}= & \text { linear regression coefficient of dependent } \\
& \text { variable } y \text { on age effect, } \\
\beta_{2}= & \text { quadratic regression coefficient of depen- } \\
& \text { dent variable } y \text { on age effect, } \\
X_{\text {age }}= & \text { continuous variable representing age of an- } \\
& \text { imal at measurement, } \\
A_{l}= & \text { random additive genetic effect of animal } 1, \\
& \text { and } \\
e_{i j k l}= & \text { random residual. }
\end{aligned}
$$

Stage effects were based on month of lactation and included eleven classes. The mean sizes of the herdrounder-classifier classes were 6 and 13, 13 and 16, and 7 and 9 for the tie and free stall, solid and slatted flooring, and no trim and trim groups, respectively. Variances were assumed to be heterogeneous across herds (within a given environment) and classifiers.

The analysis was implemented using the VCE 4.0 software of Groeneveld and Garcia-Cortes (1998). Differences in the estimates of heritabilities for the same trait across environments were examined to see whether they differed significantly from zero. To approximate the standard error of this difference, the separate standard errors were squared and summed. The square root of this quantity was then taken as the standard error of the difference. Differences in heritability greater than twice this approximate standard error were deemed significant. To test the hypothesis of significant GXE, the difference from 1.0 of the estimated genetic correlation between two traits was compared to two times the estimated standard error. 
Table 2. Overall means ( \pm standard deviations) for feet and leg traits in different management systems.

\begin{tabular}{|c|c|c|c|c|c|c|c|c|}
\hline $\begin{array}{l}\text { Scoring } \\
\text { environments } \\
\text { (N) }\end{array}$ & $\begin{array}{l}\text { Systems } \\
(\mathrm{N})\end{array}$ & \multicolumn{7}{|c|}{ Traits } \\
\hline $\begin{array}{l}\text { Housing } \\
(147,400)\end{array}$ & $\begin{array}{l}\text { Tie stall } \\
(93,664)\end{array}$ & $5.68 \pm 1.54$ & $4.69 \pm 1.26$ & $5.36 \pm 1.86$ & $4.91 \pm 1.29$ & $5.90 \pm 1.50$ & $5.13 \pm 1.37$ & $9.02 \pm 2.27$ \\
\hline $\begin{array}{l}\text { Flooring } \\
(53,550)\end{array}$ & $\begin{array}{l}\text { Slatted } \\
(5553)\end{array}$ & $5.38 \pm 1.69$ & $4.91 \pm 1.38$ & $5.07 \pm 1.79$ & $5.18 \pm 1.40$ & $5.80 \pm 1.45$ & $5.67 \pm 1.30$ & $8.97 \pm 2.33$ \\
\hline \multirow[t]{2}{*}{$\begin{array}{l}\text { Hooves } \\
(145,160)\end{array}$} & $\begin{array}{l}\text { Intact } \\
(78,063)\end{array}$ & $5.56 \pm 1.54$ & $4.76 \pm 1.32$ & $5.27 \pm 1.81$ & $4.92 \pm 1.35$ & $5.87 \pm 1.51$ & $5.26 \pm 1.36$ & $8.98 \pm 2.30$ \\
\hline & $\begin{array}{l}\text { Trimmed } \\
(67,097)\end{array}$ & $5.81 \pm 1.55$ & $4.93 \pm 1.28$ & $5.44 \pm 1.82$ & $5.20 \pm 1.35$ & $6.01 \pm 1.43$ & $5.25 \pm 1.29$ & $9.44 \pm 2.19$ \\
\hline
\end{tabular}

\section{RESULTS AND DISCUSSION}

Means and standard deviations of the seven feet and leg traits for each management system are presented in Table 2. On the basis of the results from ANOVA, the effects of the two respective management systems defined in each analysis were highly significantly different $(P<0.001)$ in all cases except for claw uniformity in the two housing groups and rear legs, side view in the two trimming groups. Between the two housing systems, most traits were on average superior among cows housed in free stalls. The largest differences (0.3 to 0.5$)$ were observed for heel depth, foot angle, rear leg side view, and overall feet and legs. Perhaps this result was associated with the fact that cattle in free stalls generally have more freedom of movement and opportunity to exercise than do cows in tie stalls. Greenough and Vermunt (1991) noted that standing on concrete was a risk factor for lameness. Alternatively, perhaps the increased moisture and manure on the floors of free-stall herds creates an opportunity for more transmission of infectious disease. In turn, culling for feet and leg problems may be more severe in these herds, resulting in higher means for phenotypic scores. Among the cows housed in free stalls, those on slatted floors tended to have slightly poorer scores for all traits than those housed on solid flooring. Boettcher and Van Dorp (1999) examined mobility scores from more than 3000 cows from free-stall herds in Ontario and observed a greater frequency of lameness among cows housed on slatted floors. Bergsten and Herlin (1996) studied lameness in a group of herds differing in a number of potential risk factors and also reported a higher rate of claw hemorrhages among cows housed on slatted floors. As expected, assuming the hoof trimming had been performed properly, scores for all traits (except rear legs, side view) were higher within herds where trimming had been performed within the 3 mo of classification. However, this trimming did not have appreciable effects on the variability of the scores. One might have expected that trimming would have most profoundly affected variability in the foot traits, claw uniformity; rear legs, rear view; and foot angle, but the standard deviations of scores were essentially equal across treatments for all three of these traits. Perhaps 3 mo was too long a period to actually observe direct effects of trimming. Recent hoof trimming may simply have been an indicator that these herds were managing foot and leg health more actively than those herds that did not trim the feet of their cattle, resulting in higher phenotypic means for the traits with little impact on variance.

Estimated heritabilities within the given management systems and genetic correlations across systems for the seven feet and leg traits are presented in Tables 3 (housing), 4 (flooring), and 5 (hoof trimming). Estimated heritabilities ranged from 0.03 for claw uniformity (several environments) to 0.29 for bone quality (cattle in tie stalls). These estimates were within the range of heritabilities reported in previous studies (e.g., Short and Lawlor, 1992; Boelling and Pollott, 1998; Foster et al., 1998) and are close to the values used for the official genetic evaluation in Canada (Canadian Dairy Network, Guelph, Ontario).

In general, the estimates based on data from cows in tie-stall environments tended slightly higher than those based on data from free stalls (Table 3), although the differences were significant only for rear legs rear view $(0.11 \mathrm{vs} .0 .08)$ and bone quality ( 0.29 vs. 0.24$)$. In general, higher heritabilities in tie stall herds were due to more additive genetic variance rather than decreased residual variance (results not shown). The differences in heritabilities between housing systems were greater for leg traits than for feet traits. Perhaps the restriction in movement and need to stand for longer periods of time on concrete in tie-stall situations allows for the expres- 
Table 3. Estimated heritabilities and genetic correlations (and their standard errors) for feet and leg traits evaluated in two housing systems.

\begin{tabular}{|c|c|c|c|c|c|}
\hline \multirow[b]{2}{*}{$\underline{\text { Trait }}$} & \multicolumn{3}{|c|}{ Heritability } & \multicolumn{2}{|c|}{ Genetic correlation } \\
\hline & Tie stall & Free-stall & $\mathrm{SE}_{\text {diff }}^{1}$ & $r_{g}$ & $\mathrm{SE}$ \\
\hline Claw uniformity & 0.03 & 0.04 & 0.01 & 0.98 & 0.03 \\
\hline Depth of heel & 0.07 & 0.06 & 0.01 & 0.90 & 0.06 \\
\hline Rear legs, rear view & 0.11 & 0.08 & 0.01 & 0.79 & 0.07 \\
\hline Foot angle & 0.12 & 0.11 & 0.01 & 0.89 & 0.05 \\
\hline Bone quality & 0.29 & 0.24 & 0.02 & 0.94 & 0.02 \\
\hline Rear legs, side view & 0.21 & 0.20 & 0.01 & 0.86 & 0.04 \\
\hline Feet and legs & 0.17 & 0.15 & 0.01 & 0.88 & 0.03 \\
\hline
\end{tabular}

${ }^{1}$ Square root of the sum of squared standard errors of heritabilities in the two different environments.

sion of more genetic variability for the leg traits. The genetic correlations between environment were significantly different from 1.0 for rear legs, both side and rear view; foot angle; bone quality; and overall feet and legs, indicating a certain level of GXE for these traits. However, only for rear legs, rear view (0.78) was the correlation below 0.80 , the level that indicates biologically important GXE, according to Robertson (1959). Cows in tie-stall herds are less likely to be observed while walking than are cows in free-stall herds, and this factor may have affected scoring for rear legs, rear view.

Between flooring systems (Table 4) heritabilities were generally higher when measured on cows housed on slatted floors. The magnitude of these differences was comparable to the differences for housing systems, but these data included fewer observations and thus standard errors were higher and none of the differences in heritability across environments were statistically significant. The mean scores (Table 2) of the feet and leg traits suggest that slatted floors are a slightly harsher environment than solid floors, and this may allow for more expression of genetic variance for these traits. As had been observed for different housing systems, the correlation between environments was lowest for rear legs, rear view (0.82). This correlation was not significantly different from the threshold of 0.80 proposed by Robertson (1959). Perhaps the necessity for cows to place their feet in a certain position with respect to the open spaces between slats in the floor affected scoring for this trait.

Table 5 gives results for estimates in herds where the hooves of cattle were left intact or trimmed within the 3 mo previous to classifying. No differences in heritabilities were observed between environments. Also, no evidence of GXE was observed, as no estimates of genetic correlations were significantly different from 1.0. In fact, for only claw uniformity was the correlation less than 0.99 . One interpretation of these results is that active management of feet and legs health improved the phenotypic scores (Table 2) of all cows by a similar degree and thus had little effect on genetic parameters. As mentioned earlier, the definition of "recently trimmed" as "within the last $3 \mathrm{mo"} \mathrm{may} \mathrm{have} \mathrm{been} \mathrm{too} \mathrm{liberal} \mathrm{to} \mathrm{ob-}$ serve actual effects due directly to trimming. The hoof trimming may have occurred too far in advance of the classification for the observation of major effects on genetic parameters. Perhaps differences would have been evident if only herds with very recent hoof trimming (such as within the last month) had been considered, but the exact date of trimming had not been recorded.

\section{CONCLUSIONS}

Effects of different environments and management systems on conformation of feet and legs were more pro-

Table 4. Estimated heritabilities and genetic correlations (and their standard errors) for feet and leg traits evaluated in free stalls with two types of flooring.

\begin{tabular}{|c|c|c|c|c|c|}
\hline \multirow[b]{2}{*}{ Trait } & \multicolumn{3}{|c|}{ Heritability } & \multicolumn{2}{|c|}{ Genetic correlation } \\
\hline & Solid & Slatted & $\mathrm{SE}_{\text {diff }}^{1}$ & $r_{g}$ & $\mathrm{SE}$ \\
\hline Claw uniformity & 0.03 & 0.03 & 0.02 & 0.85 & 0.13 \\
\hline Depth of heel & 0.06 & 0.09 & 0.02 & 0.92 & 0.07 \\
\hline Rear legs, rear view & 0.07 & 0.09 & 0.02 & 0.82 & 0.08 \\
\hline Foot angle & 0.09 & 0.12 & 0.02 & 0.86 & 0.06 \\
\hline Bone quality & 0.24 & 0.26 & 0.03 & $>0.99$ & 0.01 \\
\hline Rear legs, side view & 0.19 & 0.17 & 0.03 & 0.97 & 0.02 \\
\hline Feet and legs & 0.13 & 0.17 & 0.02 & 0.87 & 0.05 \\
\hline
\end{tabular}

${ }^{1}$ Square root of the sum of squared standard errors of heritabilities in the two different environments. 
Table 5. Estimated heritabilities and genetic correlations (and their standard errors) for feet and leg traits evaluated upon cows with intact or recently trimmed hooves.

\begin{tabular}{lllllll}
\hline & \multicolumn{3}{c}{ Heritability } & & \multicolumn{2}{c}{ Genetic correlation } \\
\cline { 2 - 3 } Trait & Intact & Trimmed & $\mathrm{SE}_{\text {diff }}{ }^{2}$ & & $\mathrm{r}_{\mathrm{g}}$ & $\mathrm{SE}$ \\
\hline Claw uniformity & 0.04 & 0.03 & 0.01 & 0.88 & 0.07 \\
Depth of heel & 0.06 & 0.07 & 0.01 & 0.99 & 0.02 \\
Rear legs, rear view & 0.10 & 0.08 & 0.02 & 0.99 & 0.01 \\
Foot angle & 0.11 & 0.11 & 0.01 & $>0.99$ & 0.01 \\
Bone quality & 0.27 & 0.24 & 0.02 & $>0.99$ & 0.01 \\
Rear legs, side view & 0.21 & 0.18 & 0.02 & 1.00 & 0.00 \\
Feet and legs & 0.17 & 0.15 & 0.02 & 0.99 & 0.01 \\
\hline
\end{tabular}

${ }^{1}$ Square root of the sum of squared standard errors of heritabilities in the two different environments.

nounced for phenotypic scores than for genetic parameters. Cows housed in free stalls had higher scores for most traits than did cows housed in tie stalls. Cows housed on slatted floors had lower scores than did cows housed on solid flooring. Trimming of hooves was associated with improved scores, but variability in scores was unaffected. Heritabilities tended to be higher when measured in the environment associated with lower scores. Perhaps the more stressful environment allowed for more expression of genetic variance. Little effect of trimming was observed for estimates of genetic parameters.

Effects of GXE across environments were not large for most traits, but genetic correlations across both housing and flooring environments were only about 0.80 for rear legs, rear view. Therefore, the current across-herd system of genetic evaluations for feet and leg traits can be expected to predict daughter performance relatively well regardless of housing, flooring, and hoof trimming management systems. No major changes to the current system seem necessary. Holstein Canada has directed specific effort to the coordination of scoring for rear legs, rear view, adopting procedures to increase the consistency of scores for cattle evaluated while standing versus on the walk.

\section{REFERENCES}

Animal and Plant Health Inspection Service. 1996. Part 1. Reference of 1996 Dairy Management Practices. National Animal Health Monitoring System. United States Dept. Agr. Fort Collins, CO.

Begsten, C., and A. H. Herlin. 1996. Sole haemorrhages and heel horn erosion in dairy cows: the influence of housing system on their prevalence and severity. Acta Vet. Scand. 37:395-408.

Boelling, D., and G. Pollott. 1998. Locomotion, lameness, hoof and leg traits in cattle. II. Genetic relationships and breeding values. Livest. Prod. Sci. 54:205-215.

Boettcher, P. J., L. K. Jairath, K. R. Koots, and J. C. M. Dekkers. 1997. Effects of interactions between type traits and milk production on survival traits of Canadian Holsteins. J. Dairy Sci. 80:2984-2995.
Boettcher, P. J., and R. van Dorp. 1999. Are your lame cows also your thin cows? Hoard's Dairyman. 144(4):140.

Burke, B. P., and D. A. Funk. 1993. Relationship of linear type traits and herd life under different management systems. J. Dairy Sci. 76:2773-2782.

DeJong, G., A. R. Vollema, S. van der Beek, and A. Harbers. 1999. Breeding value for functional longevity in the Netherlands. Proc. Int. Workshop EU Concerted Action Genet. Improvement of Functional Traits in Cattle; Longevity. Interbull Bull. No. 19:68-72.

Enevoldsen, C., Y. T. Grohn, and I. Thysen. 1991. Heel erosion and other interdigital disorders in dairy cows: associations with season, cow characteristics, disease, and production. J. Dairy Sci. 74:1299-1309.

Enting, H., D. Kooij, A. A. Dijkhuizen, R. B. M. Huirne, and E. N. Noordhuizen-Stassen. 1997. Economic losses due to clinical lameness in dairy cattle. Livest. Prod. Sci. 49:259-267.

Foster, W. W., A. E. Freeman, and P. J. Berger. 1988. Linear type traits analysis with genetic parameter estimation. J. Dairy Sci. 71:223-231.

Foster, W. W., A. E. Freeman, P. J. Berger, and A. Kuck. 1989. Association of type traits scored linearly with production and herdlife of Holsteins. J. Dairy Sci. 72:2651-2664.

Gilmore, J. A. 1978. The effect of housing, age, breed and time after trimming on hoof measurements. J. Dairy Sci. 61(Suppl. 1):83. (Abstr.)

Greenough, P. R., and A. D. Weaver. 1997. Lameness in Cattle. W. B. Saunders. Philadelphia, PA.

Greenough, P. R., and Vermunt, J. J. 1991. Evaluation of subclinical laminitis in a dairy herd and observations on associated nutritional and management factors. Vet. Rec. 128:11-17.

Groeneveld, E., and A. Garcia-Cortes. 1998. VCE4.0, a covariance component package for frequentists and Bayesians. Proc. 6th World Congr. Genet. Appl. Livest. Prod. 27:455-456.

McDaniel, B. T. 1997. Breeding programs to reduce foot and leg problems. Proc. Int. Workshop EU Concerted Action Genet. Improvement of Functional Traits in Cattle; Health. Interbull Bull. No. $15: 115-122$

Passman, E., and F. Reinhardt. 1999. Genetic relationships between type composites and length of productive life of black-and-white Holstein cattle in Germany. Proc. Int. Workshop EU Concerted Action Genet. Improvement of Functional Traits in Cattle; Longevity. Interbull Bull. No. 19:117-121.

Robertson, A. 1959. The sampling variance of the genetic correlation coefficient. Biometrics 15:469-485.

Short, T. H., and T. J. Lawlor. 1992. Genetic parameters of conformation traits, milk yield, and herd life in Holstein. J. Dairy Sci. 75:1987-1998.

Vermunt, J. J., and P. R. Greenough. 1996. Claw conformation of dairy heifers in two management systems. Br. Vet. J. 152:3, 321-331. 